\title{
Numerical Study of Piles Group under Seismic Loading in Frictinal Soil-Inclination Effect
}

\author{
Fadi Hage Chehade ${ }^{1}$, Marwan Sadek ${ }^{2}$, Douaa Bachir ${ }^{3}$ \\ ${ }^{1}$ Civil Engineering Department, Doctotral School of Sciences and Technology, Lebanese University, \\ University Institute of Technology (Saida) \& Modeling Center, Beirut, Lebanon \\ ${ }^{2}$ Laboratory of Civil Engineering and GeoEnvironment, \\ University of Lille I Sciences and Technology, Villeneuve d'Ascq, France \\ ${ }^{3}$ Numerical Center, Doctoral School of Science and Technology, Lebanese University, Beirut, Lebanon \\ Email: fchehade@ul.edu.lb
}

Received November 22, 2013; revised December 28, 2013; accepted February 6, 2014

Copyright (c) 2014 Fadi Hage Chehade et al. This is an open access article distributed under the Creative Commons Attribution License, which permits unrestricted use, distribution, and reproduction in any medium, provided the original work is properly cited. In accordance of the Creative Commons Attribution License all Copyrights @ 2014 are reserved for SCIRP and the owner of the intellectual property Fadi Hage Chehade et al. All Copyright (C) 2014 are guarded by law and by SCIRP as a guardian.

\begin{abstract}
Recent devastating earthquakes in some countries, such as Pakistan, Turkey, Algeria and China, call to the mind the high risk exposure of Lebanon which is located over an active seismic zone. Many experts shared the view that major seismic event may occur in Lebanon in the future. Moreover, many earthquakes, of low magnitudes between three and four, have been registered in Lebanon during 2008. These events have increased the anxiety of Lebanese people because of the poor quality of the constructions and their behavior under moderate or severe earthquake events. The efficient way to minimize seismic effects, material and human losses, is the prevention. The system piles-foundation is an appropriate way and widely used to ensure the stability of constructions when subjected to seismic excitation. It seems necessary to study the interaction of pile-foundation-pile-cap-structure in the case of non linear soil behavior and the interface pile-soil. The study will be also conducted by using measures recorded during real earthquakes for example in Turkey (Kocaeli, 1999). In this paper, we present a numerical modeling of the interaction of using FLAC3D software. According to soil behavior and pile inclination, parametric studies are also performed. The analysis of the results could give the better piles group configuration in order to minimize the seismic effect on the structures.
\end{abstract}

\section{KEYWORDS}

Frictional Soil; Inclination; Interaction; Non Linear; Numerical Modeling; Piles Group

\section{Introduction}

Recent devastating earthquakes in some countries, such as Pakistan, Turkey, Algeria and China, call to the mind the high risk exposure of Lebanon which is located over an active seismic zone. There are some faults in the country represented respectively by major and secondary ones. Many geologic experts shared the view that major seismic event could occur in Lebanon in the future. Moreover, many earthquakes, of low magnitudes between three and four, have been registered in Lebanon during 2008. These events have increased the anxiety of Lebanese people because of the poor quality of the constructions and their behavior that could undergo in the case of moderate or severe earthquake events. The efficient way to minimize seismic effects both material and human losses, is the prevention and in particular it is very important to enhance the foundations of the constructions.

Piles are used as foundation elements for structures located in seismic areas. They provide stability, but may be acquired by efforts that exceed their carrying capacity. These efforts are dangerous for piles installed in soils with low fundamental frequencies, as they amplify the seismic motion of the soil endangering the stability of these structures and their functioning.

Analysis of the seismic response of soil-pile-structure systems constitutes a complex problem in earthquake engineering. In addition to post-earthquake investigations, 
analytical and numerical analyses show that the damage of piles in seismic area is mainly attributed to the kinematic interaction between piles and soils or (and) to the inertial interaction between the superstructure and the pile foundation which may cause foundation damages, in particular at the pile-cap connection.

Due to the complexity of the problem of interaction soil-pile-structure and the strong coupling between the elements of foundation and structure, it is necessary to conduct a comprehensive analysis of this problem. Most researches have been conducted within the framework of the elasticity, considering the link between piles and soil as rigid. In the case of strong seismic loading, the nonlinearities of soil can play an important role in modifying the state of the interface soil-pile causing a strong damping of the seismic energy injected into the structure. Using advanced computing resources, the consideration of the nonlinearities of the soil and the structure becomes possible in a comprehensive approach.

Non linear full 3D analyses considering the soil, piles and the superstructure are still limited. Such studies were conducted in the linear domain ([1-5]) to analyse the influence of micropiles inclination and boundaries conditions on the seismic behaviour of the soil-micropile structure system. Gerolymos et al. [6] used a full 3D finite element analysis to study the seismic performance of inclined piles assuming a linear behaviour of the soil and the structure.

The present paper is focused on a full 3D coupled modelling of the soil-pile-superstructure interaction under seismic loading considering the elastoplastic behaviour of the soil material. Analysis is performed using the FLAC3D [7] program under real earthquake records (Kocaeli, 1999). Soil plasticity is investigated in the case of frictional soils where the soil behaviour is described using the simple and popular non-associated Mohr-Coulomb criterion largely used in engineering practice. The last part discusses the efficiency of inclined piles in seismic zones. Using inclined piles in seismic zones is generally not recommended by international codes, especially when piles are anchored in hard substrata. However, the analysis of the Loma Prieta earthquake ([8]) and Kobe $([9,10])$ showed that structures based on inclined piles were less affected or damaged than other structures.

\section{Numerical Analysis of Soil-Pile-Structure System (Elastic Soil)}

\subsection{Problem Definition}

The model that has been analyzed consists of a group of four piles of $1 \mathrm{~m}$ diameter and $10 \mathrm{~m}$ length, embedded in a homogeneous soil layer of $15 \mathrm{~m}$ of thickness (Figure 1). The piles are fixed in a cap of $1 \mathrm{~m}$ thick with no con- tact with the ground, and supporting a superstructure. The spacing between piles is $S=3.75 D_{p}\left(D_{p}\right.$ : is the diameter of the pile). The behaviour of the soil-pile-structure system is firstly assumed to be elastic with Rayleigh damping. The superstructure is modelled by a single degree of freedom system, consisting of a column of height $H_{s t}=1 \mathrm{~m}$ and a concentrated mass $m_{s t}=100$ tons placed on the top of column. The fundamental frequency of the soil layer is equal to $f_{1}=0.67 \mathrm{~Hz}$. The rigidity $\left(K_{s t}\right)$ and the frequency of the superstructure $\left(f_{s t}\right)$, assumed fixed at its base, are calculated using the following expression:

$$
\begin{aligned}
& K_{s t}=\frac{3\left(E_{s t} I_{s t}\right)}{\left(H_{s t}\right)^{3}} \\
& f_{s t}=\frac{1}{2 \pi} \sqrt{\frac{K_{s t}}{m_{s t}}}
\end{aligned}
$$

Then, $K_{s t}=86400 \mathrm{kN} / \mathrm{m}$ and $f_{s t}=1.48 \mathrm{~Hz}$.

The mesh used is shown in Figure 2. A refinement is located around the piles and the area near the superstructure where the inertial forces induce high stresses. The soil basis is assumed rigid. The boundaries are placed far enough from the structure with the use of specific elements and absorbing boundaries ("free field") to reduce the reflection of waves at the edges of the model. The Soil, piles and superstructure mechanical properties are given in Table 1 . The piles have an axial rigidity $\mathrm{E}_{\mathrm{p}} \mathrm{A}_{\mathrm{p}}=$ $18850 \mathrm{MN}$ and a flexural rigidity $\mathrm{E}_{\mathrm{p}} \mathrm{I}_{\mathrm{p}}=1178 \mathrm{MN} \cdot \mathrm{m}^{2}$.

\subsection{Seismic Loading}

The soil-structure system is subjected to two types of loading. The first one corresponds to a harmonic loading with a frequency equal to the soil natural frequency. This loading has very severe consequences and may lead to high internal forces that are not representative to a real earthquake. The second one corresponds to the 1999 Kocaeli earthquake in Turkey with a frequency contents close to the natural frequencies of the soil-structure system.

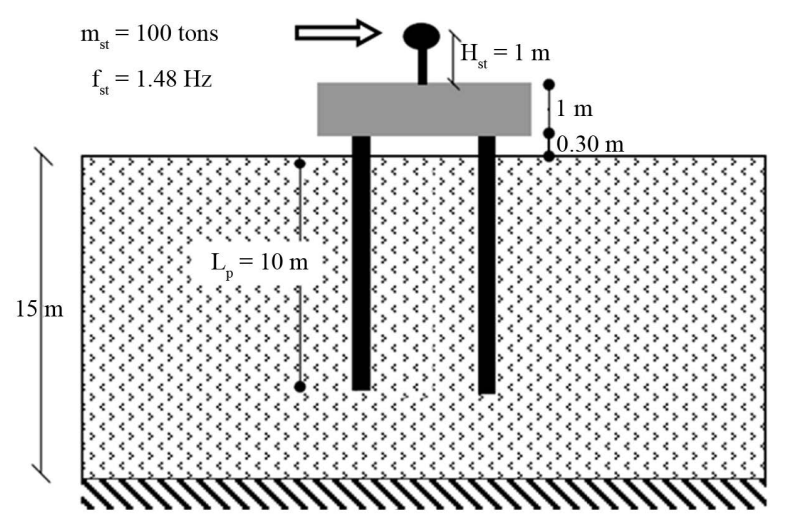

Figure 1. Problem definition. 


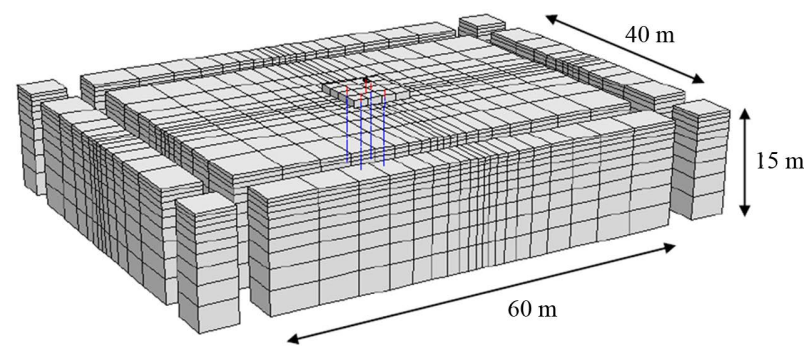

Figure 2. Mesh and boundary conditions.

Table 1. Mechanical properties of soil-pile-superstructure system.

\begin{tabular}{ccccc}
\hline & \multicolumn{4}{c}{ Mechanical properties } \\
\cline { 2 - 5 } & $\begin{array}{c}\text { Density } \\
\left(\mathrm{Kg} / \mathrm{m}^{3}\right)\end{array}$ & $\begin{array}{c}\text { Young } \\
\text { modulus }(\mathrm{MPa})\end{array}$ & $\begin{array}{c}\text { Poisson’s } \\
\text { ratio }\end{array}$ & $\begin{array}{c}\text { Damping } \\
\text { ratio }\end{array}$ \\
\hline Soil & 1700 & 8 & 0.3 & $\xi=5 \%$ \\
Pile & 2500 & 24,000 & 0.3 & $\xi=5 \%$ \\
Structure & 2500 & 24,000 & 0.3 & $\xi=5 \%$ \\
\hline
\end{tabular}

In the first step, numerical simulations were performed in the case of a harmonic load of 10 cycles, with a frequency equal to the fundamental frequency of the soil ( $\mathrm{f}_{\text {loading }}=\mathrm{f}_{1, \text { sol }}=0.67 \mathrm{~Hz}$ ), and an acceleration amplitude of $0.2 \mathrm{~g}\left(\mathrm{~V}_{\mathrm{g}}=0.46 \mathrm{~m} / \mathrm{s}\right)$.

In a second step, a real loading is applied as a velocity at the base of the soil mass. The record for the base acceleration, velocity, and displacement waves are shown in Figure 3. It marks a maximum speed of $40 \mathrm{~cm} / \mathrm{s}$ and a maximum acceleration of $0.247 \mathrm{~g}$. Fourier analysis of the record of the earthquake's velocity results in a power spectrum that reveals a dominant frequency at $\mathrm{f}=0.9 \mathrm{~Hz}$ (lower peaks are observed at 0.6 and $1.3 \mathrm{~Hz}$ ) to be compared with the natural frequencies of the soil $(0.67 \mathrm{~Hz})$ and the superstructure $(1.4 \mathrm{~Hz})$. The Kocaeli earthquake has been chosen because it has frequency contents close to the natural frequencies of the soil-structure system which enhance the development of soil plasticity.

\subsection{Comparison of Dynamic Forces in the Piles}

The forces induced in the piles due to the real seismic loading of Kocaeli, of frequency $\mathrm{f}=0.9 \mathrm{~Hz}$, are represented in Table 2 and Figure 4, compared with forces induced in piles due to the harmonic loading of frequency $f$ $=0.67 \mathrm{~Hz}$. Figure 4 shows a significant influence of the dominant frequency loading that can lead to significant efforts values exceeding the bearing capacity of piles and especially when this frequency equals to the natural frequency of the soil. Harmonic loading is very detrimental and causes excessive forces compared to real earthquake loading. So, only real record is used in the next analysis.
Table 2. Piles response for different types of loading.

\begin{tabular}{ccccc}
\hline Loading & $\begin{array}{c}\text { Acc mass } \\
\left(\mathrm{m} / \mathrm{s}^{2}\right)\end{array}$ & $\begin{array}{c}\text { Acc cap } \\
\left(\mathrm{m} / \mathrm{s}^{2}\right)\end{array}$ & $\begin{array}{c}\text { Max shear } \\
\text { force V }(\mathrm{KN})\end{array}$ & $\begin{array}{c}\text { Max. bending } \\
\text { moment M } \\
(\mathrm{KN} . \mathrm{m})\end{array}$ \\
\hline $\begin{array}{c}\text { Sinusoidal } \\
\text { Turkey } \\
\text { (Kocaeli) }\end{array}$ & 34.71 & 33.1 & 854.8 & 3137 \\
\hline
\end{tabular}

\section{Effect of Soil Plasticity}

This section deals with the effect of nonlinearities on the behaviour of the soil-pile-structure system, in particular, the influence of soil plasticity on the system response. Numerical simulations are performed using real seismic loading (Turkey, Kocaeli, 1999). The soil behavior is described by an elastic-perfectly plastic Mohr-Coulomb. The case relative to frictional soil is presented in this section.

\subsection{Plastic Calculation}

A parametric study was conducted to know the effect of plasticity for frictional soil on the seismic behaviour of the soil-pile-structure system. The friction angle is considered of $30^{\circ}$ and a low cohesion of $2 \mathrm{KPa}$. To know the influence of dilancy angle, two values were chosen $\psi=$ $0^{\circ}$ and $\psi=20^{\circ}$. A slight damping of Rayleigh is used for the soil. The behaviour of the cap-structure system is assumed to be elastic.

The extension of plasticity is shown in Figure 5. We can note that the plasticity is localized near the surface due to the low soil confinement at this zone. The seismic loading induces plasticity at the top of soil and the energy is injected into the structure. Plasticization of the soil around the pile head makes it weaker; it leads to the formation of a gap around the pile head which confirms the post seismic observations.

\subsection{Effect of soil Behavior}

Figure 6 shows the internal stresses induced in piles. The variation of the maximum shear force at the top is related to the change of acceleration. For the bending moment, the results at the top are not significantly affected by the change of the dilancy angle. The results are illustrated in Table 3. This parametric study considers two extreme cases of dilancy angles, the intermediate values between $0^{\circ}$ and $20^{\circ}$ lead to similar tendencies.

\section{Effect of Piles Inclination}

The effect on the pile inclination on the seismic answer of the system pile-soil-cap is investigated in this section. The case that has been modelled is similar to that earlier, except that the four piles are inclined outwardly. To properly analyze the influence of pile inclination on their 

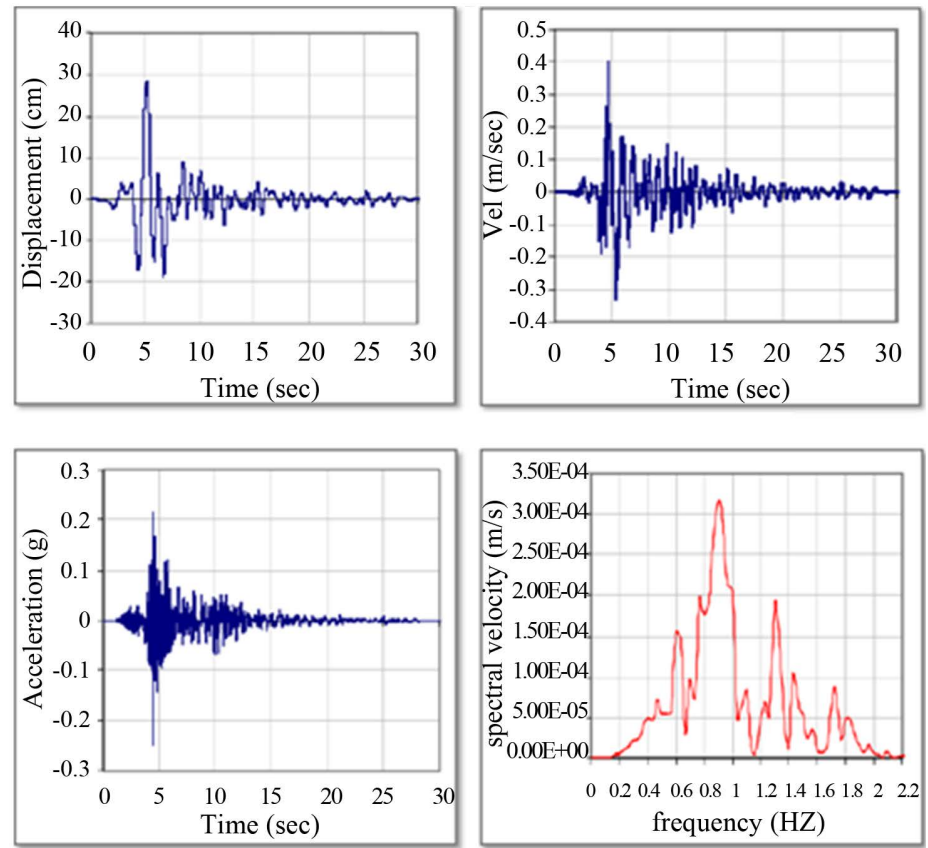

Figure 3. Data of Kocaeli earthquake (Turkey, 1999).
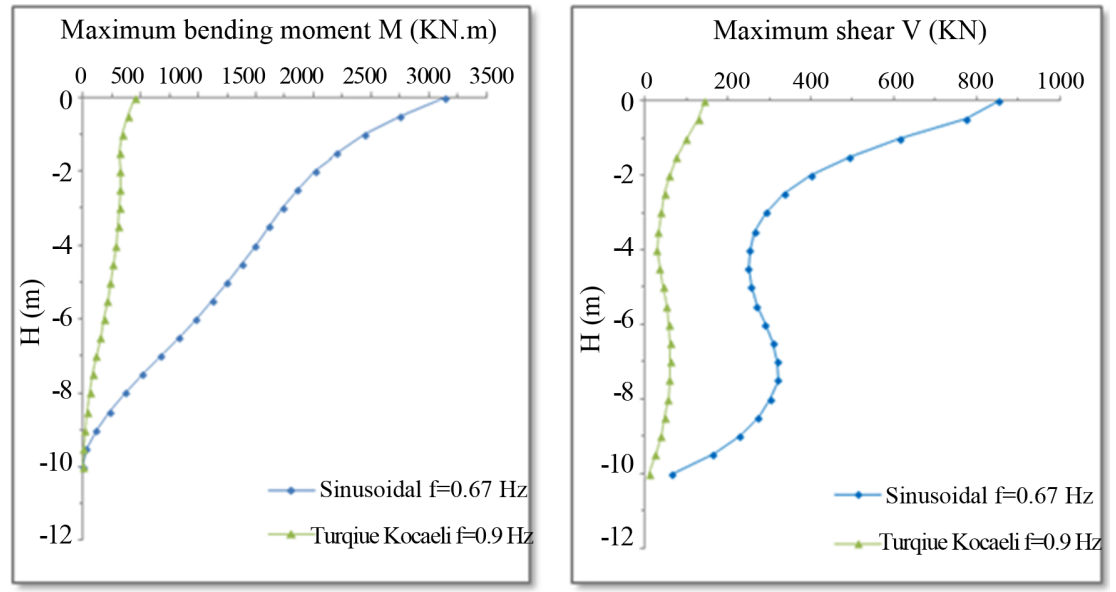

Figure 4. Maximum dynamic forces in the piles.

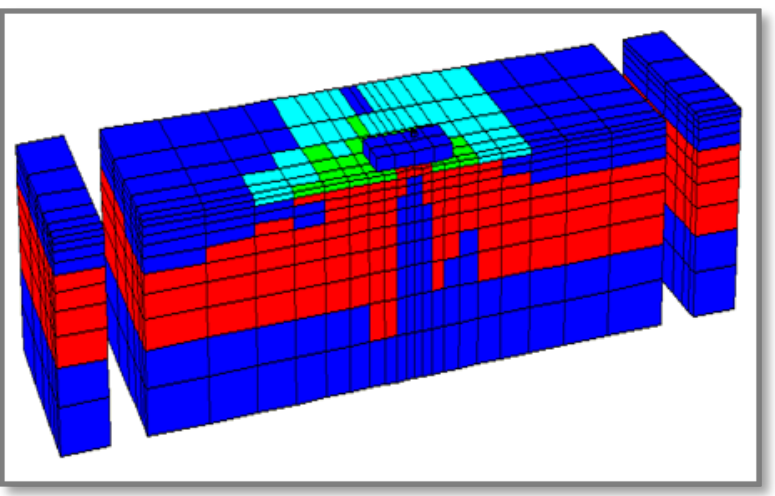

(a)

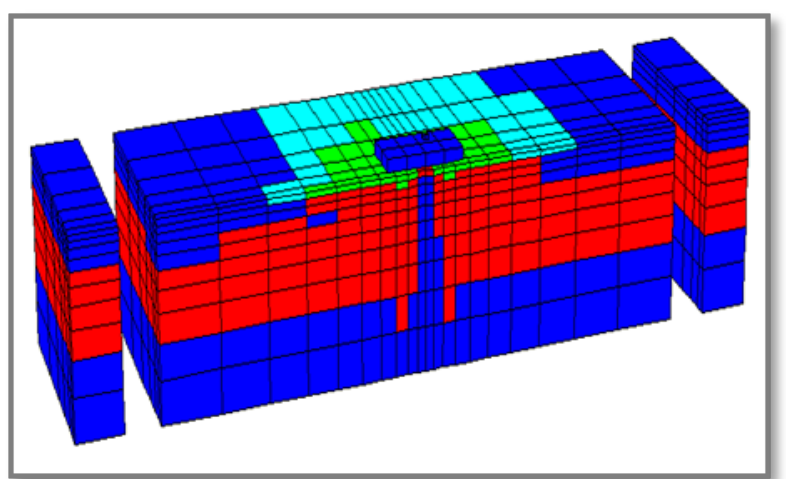

(b)

Figure 5. Plasticity extension in the case of frictional soil $\left(\mathrm{C}=2 \mathrm{KPa}, \psi=0^{\circ}\right.$ and $\left.\psi=20^{\circ}\right) .\left(\right.$ a) $\psi=0^{\circ},(\mathrm{b}) \psi=20^{\circ}$. 

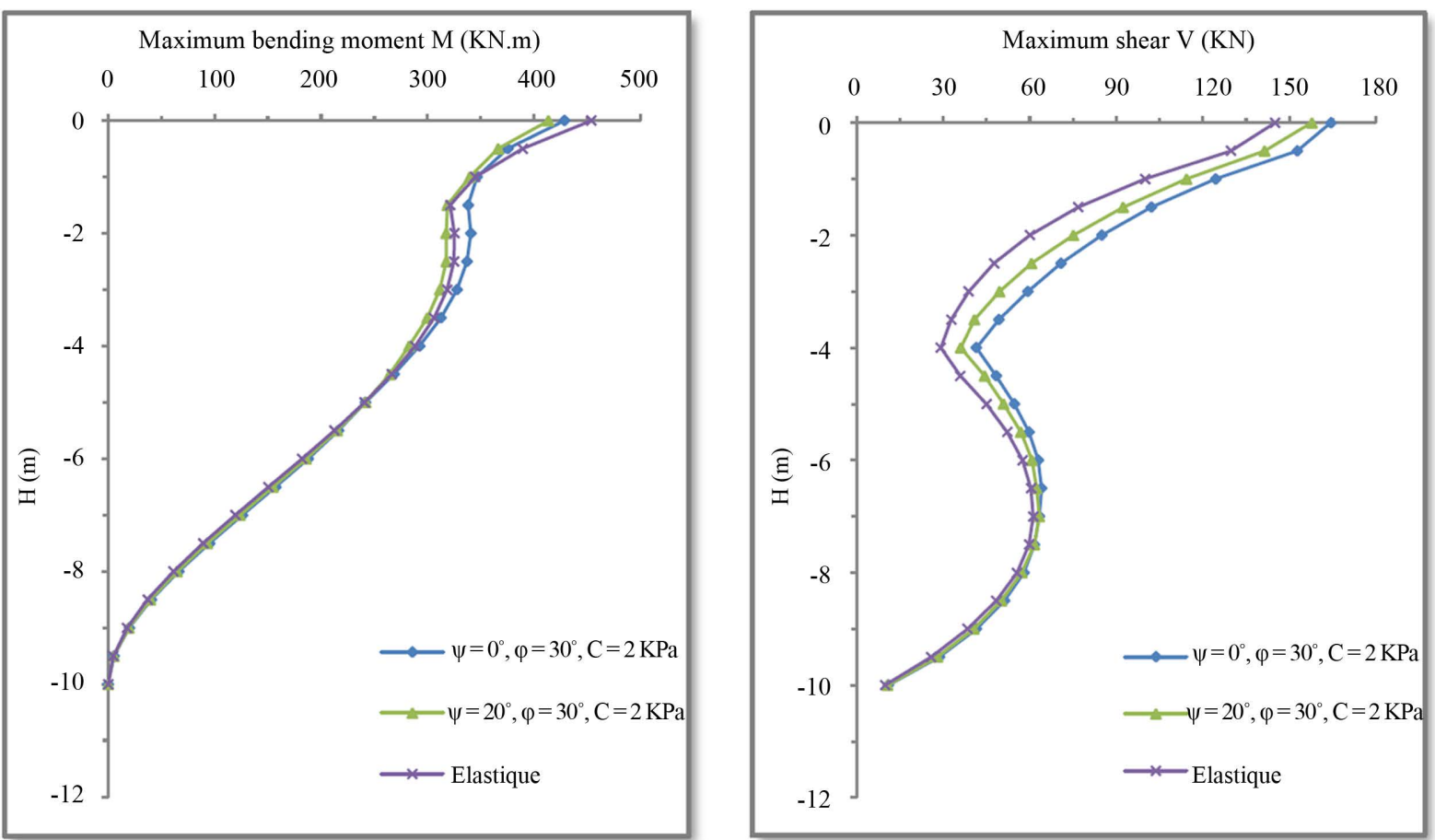

Figure 6. Influence of frictional soil plasticity on the dynamic forces in the piles (Kocaeli earthquake, Turkey, 1999).

Table 3. Influence of frictional soil plasticity on the dynamic forces in the piles.

\begin{tabular}{ccccc}
\hline$\psi\left({ }^{\circ}\right)$ & $\begin{array}{c}\text { Acc mass } \\
\left(\mathrm{m} / \mathrm{s}^{2}\right)\end{array}$ & $\begin{array}{c}\text { Acc cap } \\
\left(\mathrm{m} / \mathrm{s}^{2}\right)\end{array}$ & $\begin{array}{c}\text { Max shear } \\
\text { force } \\
\mathrm{V}(\mathrm{KN})\end{array}$ & $\begin{array}{c}\text { Max. bending } \\
\text { moment M } \\
(\mathrm{KN} . \mathrm{m})\end{array}$ \\
\hline Elastic & 7.36 & 5.4 & 145 & 453.8 \\
$0^{\circ}$ & 7.431 & 5.775 & 164.3 & 428.5 \\
$20^{\circ}$ & 7.391 & 6.147 & 157.7 & 413.6 \\
\hline
\end{tabular}

seismic response, results of calculations are presented for the two values of inclination angles respectively $\alpha=10^{\circ}$ and $\alpha=20^{\circ}$. The results are summarized in Figure 7 and Table 4. For the example presented here, the inclination of the pile leads to a reduction of the numerical values of the normal load and lateral displacement of the pile group. However we can remark that along the pile, the values of the moment and the shear have been increased. Table 4 illustrates that on the maximal values of internal forces and the amplification at cap and the structure head have been reduced when the value of the inclination increases except for the value of the bending moment.

\section{Conclusions}

In this paper, we present a three-dimensional numerical modeling of the soil-pile-structure interaction under seismic loading. The effect of the plasticity has been investigated in the case of a frictional soil as well as the effect of the dilancy angle. The numerical modeling has been
Table 4. Influence of inclination on the seismic response of pile groups.

\begin{tabular}{cccc}
\hline Inclination & $\alpha=0^{\circ}$ & $\alpha=10^{\circ}$ & $\alpha=20^{\circ}$ \\
\hline Amplification at the head of cap & 5.40 & 5.217 & 3.445 \\
Amplification at the head of structure & 7.36 & 6.526 & 3.580 \\
Maximum bending moment M (KN.m) & 453.8 & 584.6 & 657.6 \\
Maximum shear force T (KN) & 145 & 122.8 & 116.5 \\
Maximum axial force N (KN) & 681.1 & 633.4 & 446.8 \\
\hline
\end{tabular}

carried by using harmonic excitation and real seismic loading recorded during the Kocaeli earthquake (Turkey, 1999). The effect of the pile inclination has been also analyzed. For simplicity, we consider the case that the piles are embedded in a homogeneous soil. The case of heterogeneous soil could be treated in the future.

The harmonic loading leads to high values of the internal forces (Bending moment, shear) especially when the frequency of the load is near to the proper frequency of the soil. For the example treated here, the plasticity of the soil has a minor effect on the results. For frictional soil, the plasticity spreads from the surface due to the low confinement of the soil in this area. Plasticisation of the soil around the piles head makes them more vulnerable, and the post seismic observations of damaged piles show the formation of a vacuum around the head of the piles.

The inclination of piles leads to a reduction in the lateral amplification of the superstructure resulting from an 


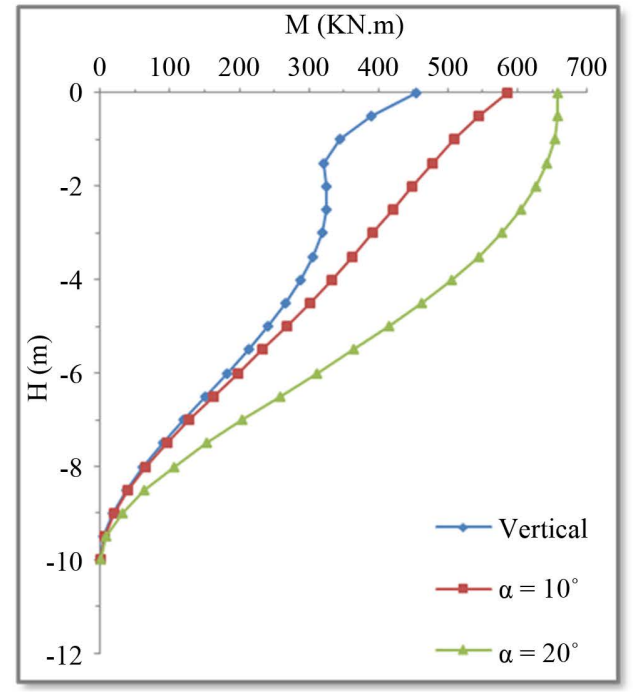

(a)

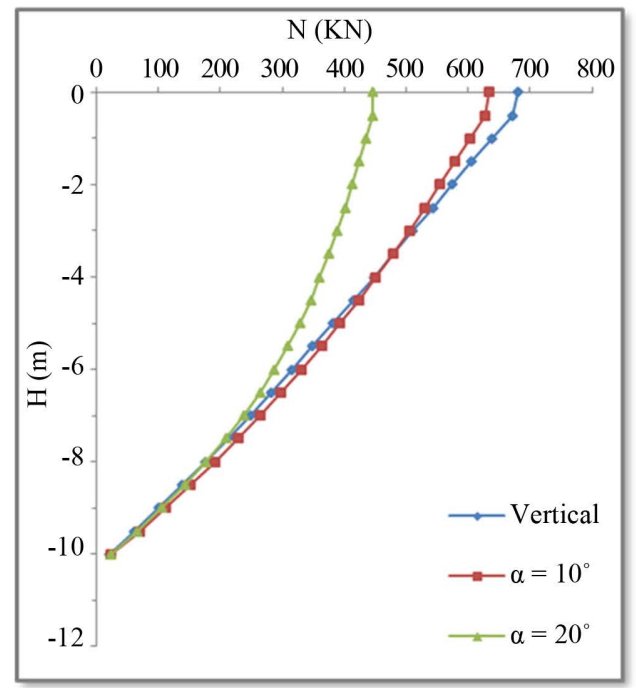

(c)

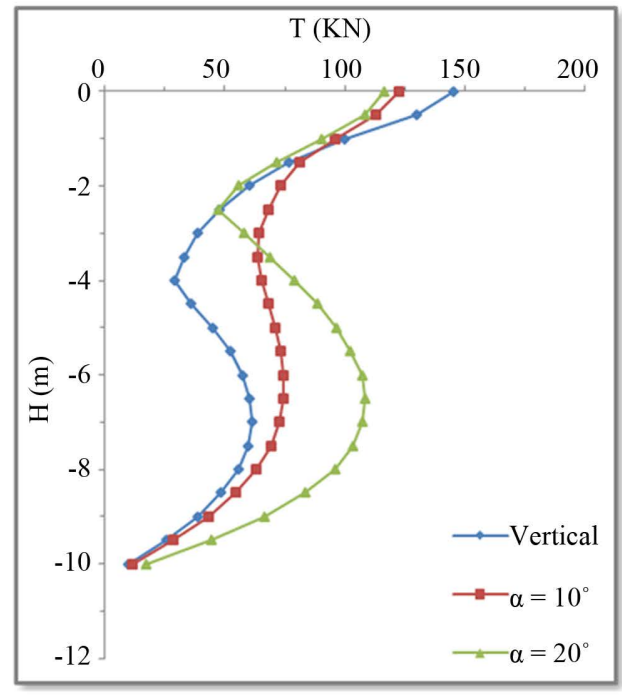

(b)

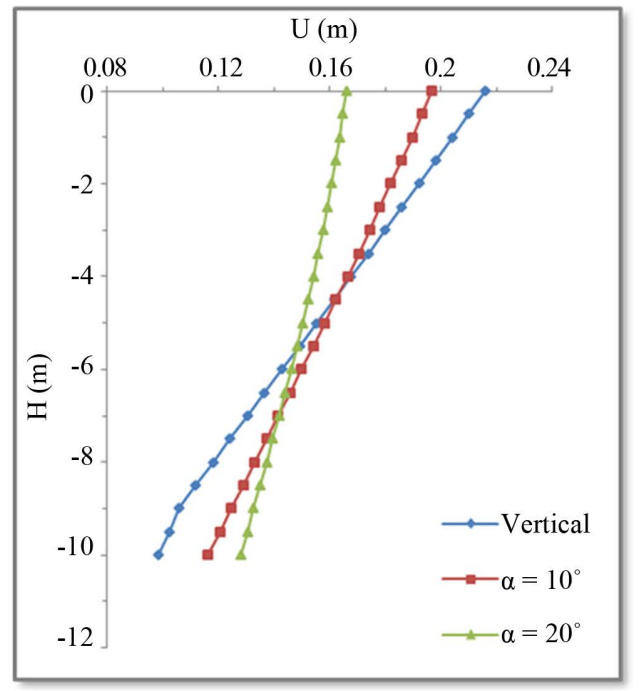

(d)

Figure 7. Influence of inclination of piles on the seismic response of pile groups (Registration of Turkey, $\mathrm{Vg}=40 \mathrm{~cm} / \mathrm{s}, \mathrm{f}=\mathbf{0 . 9}$ $\mathrm{Hz}, \mathrm{Ag}=0.247$ g). (a) Bending Moment, (b) Shear force, (c) Normal force, (d) Displacement.

increase in the rigidity of the system. The inclination of piles can be beneficial for both the dynamic behavior and the behavior of the superstructure. It depends on the interaction of the frequency of the seismic load with the frequencies of the soil-pile-structure. The inclination increases the lateral stiffness of the foundation which, unfortunately, can cause a significant increase in the load transmitted to the foundation of the superstructure. Despite the improved performance of inclined piles, the bending forces at the top of piles are still very significant.

\section{Acknowledgements}

We thank the Lebanese National Council of Scientific Research for the funding of this work.

\section{REFERENCES}

[1] M. Sadek and I. Shahrour, “Three-Dimensional Finite Element Analysis of the Seismic Behaviour of Inclined Micropiles," Soil Dynamics and Earthquake Engineering, Vol. 24, 2004, pp. 473-485.

[2] M. Sadek and I. Shahrour, "Influence of the Head and Tip Connection on the Seismic Performance of Micropiles," Soil Dynamics and Earthquake Engineering, Vol. 26, No. 6, 2006, pp. 461-468.

[3] R. W. Boulanger, C. J. Curras, D. W. Wilson and A. A. Abghari, "Seismic Soil-Pile-Structure Interaction Experiments and Analyses," Journal of Geotechnical and Geoenvironmental Engineering, Vol. 125, No. 9, 1999, pp. 750-759.

[4] Y. Chung, "Etude Numérique de L’interaction Sol-Pieu- 
Structure sous Chargement Sismique,” Thèse de Doctorat, Université de Sciences et Technologie de Lille, 2000.

[5] N. Gerolymos, A. Giannakou, I. Anastasopoulos and G. Gazetas, "Evidence of Beneficial Role of Inclined Piles: Observations and Summary of Numerical Analyses," Springer Science and Business Media B. V., 2008.

[6] N. Gerolymos, S. Escoffier, G. Gazetas and J. Garnier, "Numerical Modeling of Centrifuge Cyclic Lateral Pile Load Experiments," Earthquake Engineering and Engineering Vibration, Vol. 8, No. 1, 2009, pp. 61-76.

[7] Itasca Consulting Group, FLAC, "Fast Lagrangian Analysis of Continua,” Vol. I. User’s Manual, Vol. II. Verification Problems and Example Applications, 2nd Edition (FLAC3D Version 3.0), Minneapolis, Minnesota, 2005.

[8] J. P. Bardet, I. M. Idriss, O’Rourke, N. Adachi, M. Hama- da and K. Ishihara, "North America-Japan Workshop on the Geotechnical Aspects of the Kobe,” Loma 138 Prieta, and Northridge Earthquake. Report No. 98-36 to National Science Foundation, Air Force Office of Scientific Research, and Japanese Geotechnical Society, Osaka, 1996.

[9] K. Tokimatsu, H. Arai and Y. Asak, "Deep Shear Structure and Earthquake Ground Motion. Characteristics in Sumiyoshi Area, Kobe City, Based on Microtremor Measurements,” Journal of Structural Engineering (ASCE), Vol. 491, 1997, pp. 37-45.

[10] G. Gazetas and G. Mylonakis, "Seismic Soil-Structure Interaction: New Evidence and Emerging Issues. Emerging Issues Paper, Geotechnical Special Publication No 75, ASCE, 2111," Soil Dynamics and Earthquake Engineering, Vol. 26, No. 6, 2006, pp. 461-468. 